Pacific Journal of Mathematic

Wrs ON KLEN S Strerac 


\title{
ANALYTIC SHEAVES ON KLEIN SURFACES
}

\section{Newcomb GREenleaF}

\begin{abstract}
Morphisms of Klein surfaces are discussed from the sheaf-theoretic standpoint, and the cohomology of an analytic sheaf on a Klein surface is computed.
\end{abstract}

o. Let $\mathfrak{X}$ be a Klein surface [1], [2]; that is, $\mathfrak{X}$ consists of an underlying space $X$, which is a surface with boundary, and a family of equivalent dianalytic atlases on $X$. If $\left(U_{\alpha}, z_{\alpha}\right)$ is such an atlas, then $z_{\alpha}: U_{\alpha} \rightarrow C^{+}$is a homeomorphism of the open set $U_{\alpha}$ in $X$ onto an open subset of $\boldsymbol{C}^{+}=\{z \in \boldsymbol{C} \mid \operatorname{Im}(z) \geqq 0\}$. The functions $z_{\alpha}$ must thus be real on $U_{\alpha} \cap \partial X$, and it is required that $z_{\alpha} \circ z_{\beta}^{-1}$ be dianalytic, that is, either analytic or antianalytic on each component of $z_{\beta}\left(U_{\alpha} \cap U_{\beta}\right)$.

In this paper we define the structure sheaf of $\mathfrak{X}$, show that the concept of morphism given in [1], [2] coincides with the concept of a morphism of ringed spaces, and compute the cohomology of analytic sheaves on $\mathfrak{X}$. If $\mathscr{F}$ is an analytic sheaf on $X$, and $\mathscr{F}$ is the lift of $\mathscr{F}$ to the complex double $\widetilde{\mathfrak{X}}$ of $\mathfrak{X}$, then there is a natural isomorphism

$$
H^{q}(\tilde{\mathfrak{X}}, \widetilde{\mathscr{F}}) \cong C \bigotimes_{R} H^{q}(\mathfrak{X}, \mathscr{F}) .
$$

1. The structure sheaf $\mathcal{O}_{x}$. We define the structure sheaf $\mathscr{O}_{x}=\mathscr{O}$ on $X$ as follows. If $U$ is open in $X$, let $\mathscr{C}(U)$ be the ring of holomorphic functions on $U$ (in the sense of [1], [2]). If $U \supset U^{\prime}$, then the inclusion map is a morphism of Klein surfaces and we have a natural map $\rho_{U^{\prime}}^{U}: \mathscr{O}(U) \rightarrow \mathscr{O}\left(U^{\prime}\right)$ (this is not quite an ordinary restriction map since the elements of $\mathscr{O}(U)$ are not quite functions). In particular, if $\left(U_{\alpha}, z_{\alpha}\right)$ and $\left(U_{\beta}, z_{\beta}\right)$ are dianalytic charts on $\mathfrak{X}$, $U_{\alpha} \supset U_{\beta}$, then

$$
\mathcal{O}\left(U_{\alpha}\right) \cong\left\{\begin{array}{r}
\left.f: U_{\alpha} \rightarrow C \mid f\left(U_{\alpha} \cap \partial X\right) \subset R\right\}, \\
\text { and } f \circ z_{\alpha}^{-1} \text { analytic }
\end{array}\right\}
$$

and

$$
\rho_{U_{\beta}^{\alpha}}^{U}(f)=\left\{\begin{array}{l}
f \mid U_{\beta} \text { where } z_{\alpha} \circ z_{\beta}^{-1} \text { is analytic } \\
\bar{f} \mid U_{\beta} \text { where } z_{\alpha} \circ z_{\beta}^{-1} \text { is antianalytic . }
\end{array}\right.
$$

It is easily checked that this defines a sheaf of local $R$-algebras on $\mathfrak{X}$.

Let $\mathfrak{X}, \mathfrak{Y}$ be Klein surfaces, $f: \mathfrak{Y} \rightarrow \mathfrak{X}$ a continuous map. Then $f$ is a morphism [1] if $f(\partial Y) \subset \partial X$ and if for every point $p \in Y$ there 
are dianalytic charts $(V, w)$ and $(U, z)$ at $p$ and $f(p)$, and an analytic function $h$ on $w(V)$, such that

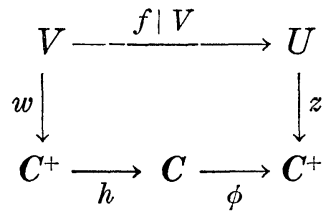

commutes $(\phi$ is the folding map, $\phi(a+b i)=a+|b| i)$.

Recall that a ringed space morphism $\mathfrak{Y} \rightarrow \mathfrak{X}$ is a pair $(f, \theta)$ where $f: Y \rightarrow X$ is continuous and $\theta: \mathscr{O}_{x} \rightarrow f_{*} \mathscr{O}_{y}$ is a morphism of sheaves of rings $\left[4\right.$, p. 36]. Here $f_{*} \mathscr{O}_{\mathrm{g}}$ is the direct image sheaf: $f_{*} \mathscr{O}_{\mathfrak{y}}(U)=$ $\mathcal{O}_{2}\left(f^{-1}(U)\right)$.

Theorem 1. Let $\mathfrak{X}, \mathfrak{Y}$ be Klein surfaces, and let $f: Y \rightarrow X$ be a nonconstant continuous map. Then the following are equivalent:

(i) $f$ is a morphism;

(ii) there exists a morphism $\theta: \mathcal{O}_{\mathfrak{x}} \rightarrow f_{*} \mathcal{O}_{\mathfrak{y}}$ of sheaves of $\boldsymbol{R}$ algebras.

Under these conditions the morphism $\theta$ is unique, so $f$ can be made in a unique way into a morphism of ringed spaces.

Proof. (i) $\Rightarrow$ (ii). Let $U \supset U^{\prime}$ be open in $X$. From the commutative diagram:

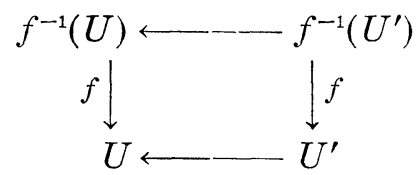

of morphisms of Klein surfaces we deduce a commutative diagram

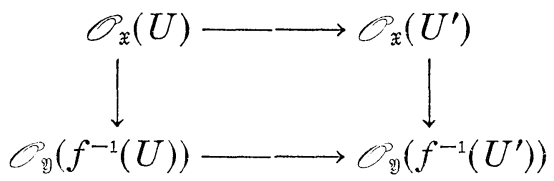

of morphisms of $\boldsymbol{R}$-algebras, and this defines an $\boldsymbol{R}$-algebra morphism $\theta: \mathscr{O}_{x} \rightarrow f_{*} \mathscr{O}_{\mathfrak{y}}$.

(ii) $\Longrightarrow$ (i ). Let $p \in Y$, and let $(V, w),(U, z)$ be dianalytic charts at $p, f(p)$, with $f(V) \subset U$. Let $z^{*}$ be the image of $z$ in $\mathscr{O}_{y}(V)$ under

$$
\mathscr{O}_{x}(U) \rightarrow \mathcal{O}_{y}\left(f^{-1}(U)\right) \rightarrow \mathscr{O}_{y}(V) .
$$

Set $h=z^{*} \circ w^{-1}$. We claim $f \mid V=z^{-1} \circ \phi \circ h \circ w$, i.e. that $z \circ(f \mid V)=$ $\phi \circ z^{*}$. It clearly suffices to show that $z(f(p))=\phi\left(z^{*}(p)\right)$. If this does not hold, then 


$$
g=\frac{1}{\left[z-z^{*}(p)\right]\left[z-\overline{z^{*}(p)}\right]}
$$

is holomorphic at $f(p)$, and shrinking $U, V$ if necessary, we may assume $g \in \mathscr{O}_{\mathfrak{x}}(U)$. We let $g^{*}$ denote its image under $\left(^{*}\right)$ in $\mathcal{O}_{\mathfrak{y}}(V)$. But $g^{*}=1 /\left[z^{*}-z^{*}(p)\right]\left[z^{*}-\overline{z^{*}(p)}\right]$ which is not defined at $p$.

We still need to show that $f(\partial Y) \subset \partial X$. Let $q \in X$. Then $\mathscr{O}_{\mathfrak{x}, q}$ is an $\boldsymbol{R}$-algebra which contains a copy of $\boldsymbol{C}$ if and only if $q \notin \partial X$. The $\mathscr{O}_{x, q}$ algebra $\left(f_{*} \mathscr{O}_{x}\right)_{q}$ is isomorphic to

$$
\prod_{f(p)=q} \mathcal{O}_{\mathfrak{g}, p},
$$

so $q \notin \partial X, f(p)=q$ implies $p \notin \partial Y$.

We now check that $\theta$ is unique. Let $U$ be open in $X, g \in \mathscr{O}_{¥}(U)$, $p \in f^{-1}(U)$. Let $(V, w)$ be a dianalytic chart at $p$ with $V \subset f^{-1}(U)$. Let $g^{*}$ be the image of $g$ in $\mathscr{O}_{y}(V)$ under $\left(^{*}\right)$. Then using the above arguments, either $g^{*}(p)=g f(p)$ or $g^{*}(p)=\overline{g f(p)}$. If $g$ is nonconstant, only one of these can yield an analytic function. If $g$ is constant it can be expressed as a sum of nonconstant functions. Hence $g^{*}$, and thus $\theta$, are uniquely determined. The theorem is proved.

By an analytic sheaf of $\mathfrak{X}$ we mean an $\mathscr{O}_{x}$-module. If $\mathscr{F}$ is an analytic sheaf on $\mathfrak{X}$ and $f: \mathfrak{Y} \rightarrow \mathfrak{X}$ is a morphism then $f^{*} \mathscr{F}$ is the sheaf associated to the presheaf $V \rightarrow \mathscr{O}_{\mathbb{Y}}(V) \boldsymbol{\otimes}_{O_{x}(f V)} \mathscr{F}(f V)$.

Proposition 2. If $\mathscr{F}$ is a coherent analytic sheaf on $\mathfrak{X}$, then $f^{*} \mathscr{F}$ is a coherent analytic sheaf on $\mathfrak{Y}$.

Proof. The proof given in [5, p. 47] for Riemann surfaces carries over to the Klein surface case.

2. The complex double. Let $\mathfrak{X}$ be a Klein surface, $\pi: \widetilde{X} \rightarrow \mathfrak{X}$ its complex double. Recall that if $\left(U_{\alpha}, z_{\alpha}\right)$ is a dianalytic atlas on $\mathfrak{X}$, then $\left(\widetilde{U}_{\alpha}, \widetilde{z}_{\alpha}\right)$ is a dianalytic atlas on $\widetilde{\mathfrak{X}}$, where $\widetilde{U}_{\alpha}=\pi^{-1}\left(U_{\alpha}\right)=U_{\alpha}^{\prime} \cup U_{\alpha}^{\prime \prime}$, $U_{\alpha}^{\prime} \cap U_{\alpha}^{\prime \prime}=\pi^{-1}\left(U_{\alpha} \cap \partial X\right)$, and $\pi$ maps $U_{\alpha}^{\prime}$ and $U_{\alpha}^{\prime \prime}$ each homeomorphically onto $U_{\alpha}$. The function $\widetilde{z}_{\alpha}$ is defined by

$$
\widetilde{z}_{\alpha}(p)= \begin{cases}z_{\alpha}(p) & p \in U_{\alpha}^{\prime} \\ \frac{z_{\alpha}(p)}{p \in U_{\alpha}^{\prime \prime}}\end{cases}
$$

$U_{\alpha}^{\prime}$ is identified with $U_{\beta}^{\prime}$ where $z_{\alpha} \circ z_{\beta}^{-1}$ is analytic, and with $U_{\beta}^{\prime \prime}$ where $z_{\alpha} \circ z_{\beta}^{-1}$ is anti-analytic. This construction yields the Riemann surface (without boundary) $\widetilde{\mathfrak{X}}$ as a double cover of $\mathfrak{X}$, folded along $\partial X$.

If $U$ is open in $X$, let $\widetilde{U}=\pi^{-1}(U)$. We denote the structure sheaf of $\tilde{\mathfrak{X}}$ by $\widetilde{\mathcal{O}}$. 
Proposition 3. There is a canonical isomorphism

$$
C \otimes_{R} \mathscr{O}(U) \cong \widetilde{O}(\widetilde{U})
$$

for every open set $U \subset X$.

Proof. We may cover $U$ by dianalytic charts $\left(U_{\alpha}, z_{\alpha}\right)$. It then suffices to verify $(\dagger)$ for $U_{\alpha}$, since $O(U)$ is the difference kernel of $\Pi_{\alpha} \widetilde{O}\left(\widetilde{U}_{\alpha}\right) \rightrightarrows \Pi_{\alpha, \beta} \widetilde{O}\left(\widetilde{U}_{\alpha} \cap \widetilde{U}_{\beta}\right)$ and $C \otimes_{R}$ is exact.

Let $\sigma$ be the canonical anti-involution of $\widetilde{\mathfrak{X}}$ which commutes with $\pi$, and let $\kappa$ denote complex conjugation. If we identify $\mathscr{O}\left(U_{\alpha}\right)$ with its image in $\widetilde{O}\left(\widetilde{U}_{\alpha}\right)$ then we see

$$
\mathscr{O}\left(U_{\alpha}\right)=\left\{g \in \widetilde{\mathcal{O}}\left(\widetilde{U}_{\alpha}\right) \mid g=\kappa g \sigma\right\} .
$$

But any $g \in \mathcal{O}\left(U_{\alpha}\right)$ can be written as

$$
g=\frac{1}{2}(g+\kappa g \sigma)+\frac{1}{2}(g-\kappa g \sigma)
$$

and hence the canonical map

$$
C \otimes_{R} \mathscr{O}\left(U_{\alpha}\right) \rightarrow \widetilde{\mathscr{O}}\left(\tilde{U}_{\alpha}\right)
$$

is surjective. This map is easily seen to be injective, completing the proof.

If $\mathscr{F}$ is an analytic sheaf on $\mathfrak{X}$, let $\mathscr{F}=\pi^{*} \mathscr{F}$.

THEOREM 4. There is a canonical isomorphism

$$
C \otimes_{R} \mathscr{F}(\mathfrak{X}) \cong \mathscr{F}(\tilde{\mathfrak{X}}) \text {. }
$$

Proof. We may choose a base for the topology of $X$ consisting of sets of the form $U_{\alpha}$, where $\left(U_{\alpha}, z_{\alpha}\right)$ is a dianalytic atlas on $X$. Then sets of the form $U_{\alpha}^{\prime}, U_{\alpha}^{\prime \prime}\left(\right.$ where $\left.U_{\alpha} \cap \partial X=\varnothing\right)$ and of the form $\widetilde{U}_{\alpha}$ (where $\left.U_{\alpha} \cap \partial X \neq \varnothing\right)$ form a base $B$ for the topology of $\tilde{\mathfrak{X}}$. Since $\widetilde{O}(\widetilde{U}) \bigotimes_{O(U)} \mathscr{F}(U) \cong C \boldsymbol{\bigotimes}_{R} \mathscr{F}(U)$, it suffices to show that the sequence

$$
\begin{aligned}
0 & \rightarrow \widetilde{\mathscr{O}}(\tilde{\mathfrak{X}}) \otimes_{O(x)} \mathscr{F}(\mathfrak{X}) \rightarrow \prod_{V \in B} \widetilde{\mathscr{O}}(V) \boldsymbol{\bigotimes}_{O(\pi V)} \mathscr{F}(\pi V) \\
& \rightarrow \prod_{V, W \in B} \widetilde{\mathscr{O}}(V \cap W) \boldsymbol{\otimes}_{0}(\pi(V \cap W)) \mathscr{F}(\pi(V \cap W)) .
\end{aligned}
$$

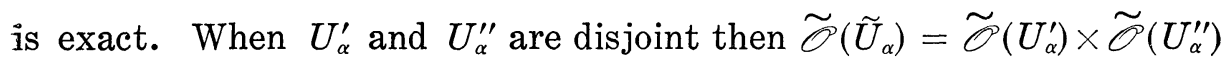
so (††) may be replaced by 


$$
\begin{aligned}
0 & \rightarrow \widetilde{\mathscr{O}}(\mathfrak{X}) \bigotimes_{o(Y)} \mathscr{F}(\mathfrak{X}) \rightarrow \prod_{\alpha} \widetilde{\mathscr{O}}\left(\widetilde{U}_{\alpha}\right) \bigotimes_{(U \alpha)} \mathscr{F}\left(U_{\alpha}\right) \\
& \rightrightarrows \prod_{\alpha, \beta} \widetilde{\mathscr{O}}\left(\widetilde{U}_{\alpha \beta}\right) \bigotimes_{O\left(U_{\alpha, \beta}\right)} \mathscr{F}\left(U_{\alpha \beta}\right)
\end{aligned}
$$

and this last is exact because of Proposition 3 and the fact that $\mathscr{F}$ is a sheaf.

Since the functors $\mathscr{F} \rightarrow C \otimes_{R} \mathscr{F}(\mathfrak{X})$ and $\mathscr{F} \rightarrow \mathscr{F}(\tilde{\mathfrak{X}})$ are canonically isomorphic, so are their derived functors [3], and we have

THEOREM 5. Let $\mathscr{F}$ be an analytic sheaf on the Klein surface $\mathfrak{X}$. Then there is a canonical isomorphism

$$
H^{q}(\tilde{\mathfrak{X}}, \tilde{\mathscr{F}}) \cong C \bigotimes_{R} H^{q}(\mathfrak{X}, \mathscr{F})
$$

for all $q \geqq 0$.

Corollary. (Cartan Theorem B) Let $\mathfrak{X}$ be a non-compact Klein surface, $\mathscr{F}$ a coherent analytic sheaf on $\mathfrak{X}$. Then $H^{q}(\mathfrak{X}, \mathscr{F})=0$ for all $q \geqq 1$

Proof. Use Theorem 5 and Proposition 2 to reduce to the case of a non-compact Riemann surface [6, p. 270].

\section{REFERENCES}

1. N. Alling and N. Greenleaf, Klein Surfaces and Real Algebraic Function Fields, Bull. Amer. Math. Soc. 75 (1969), 869-872.

2. Klein Surfaces, Springer Lecture Notes in Mathematics. (to appear).

3. A. Grothendieck, Sur Quelques Points d' Algebre Homologique, Tohoku Math. J., 9 (1957), 119-221.

4. A. Grothendieck and J. Dieudonne, Elements de Geometrie Algebrique I, Pub. I.H.E.S., 1969.

5. R. Gunning, Lectures on Vector Bundles over Riemann Surfaces, Princeton University Press, Princeton, 1967.

6. R. Gunning and H. Rossi, Analytic Functions of Several Complex Variables, Prentice Hall, Englewood Cliffs, N.J., 1965.

Received May 20, 1970. This research was partially supported by National Science Foundation grant GP-16100.

The University of Texas at Austin

Austin, TeXas 78712 



\title{
PACIFIC JOURNAL OF MATHEMATICS
}

\author{
EDITORS
}

\author{
H. SAMelson \\ Stanford University \\ Stanford, California 94305 \\ C. R. HoBBy \\ University of Washington \\ Seattle, Washington 98105
}

J. DugunduI

Department of Mathematics

University of Southern California

Los Angeles, California 90007

RICHARD ARENS

University of California

Los Angeles, California 90024

\section{ASSOCIATE EDITORS}

\author{
E. F. BeCKENBACH
}

B. H. NEUMANN

F. WoLF

K. YOSHIDA

\section{SUPPORTING INSTITUTIONS}

\author{
UNIVERSITY OF BRITISH COLUMBIA \\ CALIFORNIA INSTITUTE OF TECHNOLOGY \\ UNIVERSITY OF CALIFORNIA \\ MONTANA STATE UNIVERSITY \\ UNIVERSITY OF NEVADA \\ NEW MEXICO STATE UNIVERSITY \\ OREGON STATE UNIVERSITY \\ UNIVERSITY OF OREGON \\ OSAKA UNIVERSITY \\ UNIVERSITY OF SOUTHERN CALIFORNIA
}

\author{
STANFORD UNIVERSITY \\ UNIVERSITY OF TOKYO \\ UNIVERSITY OF UTAH \\ WASHINGTON STATE UNIVERSITY \\ UNIVERSITY OF WASHINGTON \\ AMERICAN MATHEMATICAL SOCIETY \\ CHEVRON RESEARCH CORPORATION \\ NAVAL WEAPONS CENTER
}

The Supporting Institutions listed above contribute to the cost of publication of this Journal, but they are not owners or publishers and have no responsibility for its content or policies.

Mathematical papers intended for publication in the Pacific Journal of Mathematics should be in typed form or offset-reproduced, (not dittoed), double spaced with large margins. Underline Greek letters in red, German in green, and script in blue. The first paragraph or two must be capable of being used separately as a synopsis of the entire paper. The editorial "we" must not be used in the synopsis, and items of the bibliography should not be cited there unless absolutely necessary, in which case they must be identified by author and Journal, rather than by item number. Manuscripts, in duplicate if possible, may be sent to any one of the four editors. Please classify according to the scheme of Math. Rev. Index to Vol. 39. All other communications to the editors should be addressed to the managing editor, Richard Arens, University of California, Los Angeles, California, 90024.

50 reprints are provided free for each article; additional copies may be obtained at cost in multiples of 50 .

The Pacific Journal of Mathematics is published monthly. Effective with Volume 16 the price per volume (3 numbers) is $\$ 8.00$; single issues, $\$ 3.00$. Special price for current issues to individual faculty members of supporting institutions and to individual members of the American Mathematical Society: $\$ 4.00$ per volume; single issues $\$ 1.50$. Back numbers are available.

Subscriptions, orders for back numbers, and changes of address should be sent to Pacific Journal of Mathematics, 103 Highland Boulevard, Berkeley, California, 94708.

PUBLISHED BY PACIFIC JOURNAL OF MATHEMATICS, A NON-PROFIT CORPORATION

Printed at Kokusai Bunken Insatsusha (International Academic Printing Co., Ltd.), 7-17, Fujimi 2-chome, Chiyoda-ku, Tokyo, Japan. 


\section{Pacific Journal of Mathematics}

\section{Vol. 37, No. $3 \quad$ March, 1971}

Mohammad Shafqat Ali and Marvin David Marcus, On the degree of the

minimal polynomial of a commutator operator ................ 561

Howard Anton and William J. Pervin, Integration on topological

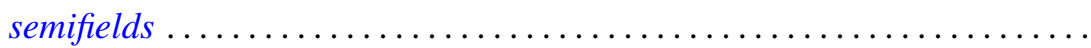

Martin Bartelt, Multipliers and operator algebras on bounded analytic

functions .................................... 575

Donald Earl Bennett, Aposyndetic properties of unicoherent continua ...... 585

James W. Bond, Lie algebras of genus one and genus two ............. 591

Mario Borelli, The cohomology of divisorial varieties ............... 617

Carlos R. Borges, How to recognize homeomorphisms and isometries ....... 625

J. C. Breckenridge, Burkill-Cesari integrals of quasi additive interval

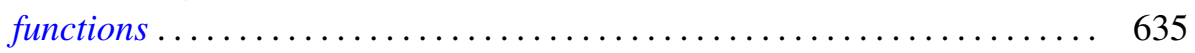

J. Csima, A class of counterexamples on permanents ................ 655

Carl Hanson Fitzgerald, Conformal mappings onto $\omega$-swirly domains . . . . . . 657

Newcomb Greenleaf, Analytic sheaves on Klein surfaces .............. 671

G. Goss and Giovanni Viglino, C-compact and functionally compact

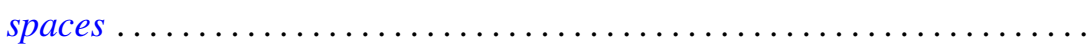

Charles Lemuel Hagopian, Arcwise connectivity of semi-aposyndetic plane

continua ..................................... 683

John Harris and Olga Higgins, Prime generators with parabolic limits ...

David Michael Henry, Stratifiable spaces, semi-stratifiable spaces, and their

relation through mappings .......................

Raymond D. Holmes, On contractive semigroups of mappings ........... 701

Joseph Edmund Kist and P. H. Maserick, BV-functions on semilattices ....... 711

Shûichirô Maeda, On point-free parallelism and Wilcox lattices ........... 725

Gary L. Musser, Linear semiprime $(p ; q)$ radicals ................. 749

William Charles Nemitz and Thomas Paul Whaley, Varieties of implicative

semilattices..................................... 759

Jaroslav Nešetřil, A congruence theorem for asymmetric trees ............ 771

Robert Anthony Nowlan, A study of $H$-spaces via left translations .......... 779

Gert Kjærgaard Pedersen, Atomic and diffuse functionals on a $C^{*}$-algebra ... 795

Tilak Raj Prabhakar, On the other set of the biorthogonal polynomials

suggested by the Laguerre polynomials...

801

Leland Edward Rogers, Mutually aposyndetic products of chainable

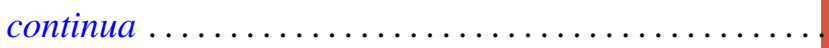

Frederick Stern, An estimate for Wiener integrals connected with squared

error in a Fourier series approximation.

Leonard Paul Sternbach, On k-shrinking and k-boundedly complete basic

sequences and quasi-reflexive spaces .................... 817

Pak-Ken Wong, Modular annihilator $A^{*}$-algebras ........ 